\title{
MODERNE THEOLOGIE EN HET NEOMARXISME, VERENIGD IN DE WERELDRAAD VAN KERKEN
}

\section{Twee motieven}

De moderne theologie wordt door twee motieven beheerst. Zij wil antwoord geven op de vragen van onze tijd. Dat is geen slecht motief. Men kan immers niet theologiseren buiten de tijd om. Het was reeds Abraham Kuyper die het verlangen had om de gereformeerde theologie weer in rapport te brengen met zijn tijd.

Natuurlijk is het wel van belang erop te letten hoé die verbinding tot stand wordt gebracht. De vraag naar een relevante theologie is niet verkeerd. Beslissend is wie uitmaakt wat relevant is. De theologie dient in elk geval praktisch van aard te zijn. De curatoren van de Leidse universiteit kregen reeds in het begin van de $17 \mathrm{e}$ eeuw de vraag onder ogen te zien of er niet een hoog. leraar benoemd kon worden die de theologie practica zou doceren. Hun antwoord was even simpel als verbluffend: elke hoogleraar dient zijn vak praktisch te behandelen. Daarmee was voor hem de kous af. Het blijkt in elk geval dat ook binnen gereformeerde kring het verlangen naar een praktische gerichte, op de praktijk aansluitende theologie reeds lang bestaat.

Een tweede motief is de krisis van het Schriftgezag. Hoe zullen we weten van God en goddelijke dingen? Alle spreken over Boven komt van beneden, ook wanneer iemand zegt dat het van boven komt. Zo ongeveer Kuitert in zijn laatste boek. Dat betekent: het gaat niet slechts door de mens heen. Het wordt mede door de mens bepaald. De mens is mede konstitutief voor wat als openbaring wordt uitgegeven.

Hier zien we de achtergrond van de kritiek op de Schrift. Het is een menselijk boek, met alle menselijke gebreken. Daar komt ook de Schrift niet boven uit. Men zegt wel eens dat het zware accent op de menselijkheid van de Schrift moet worden verstaan als reaktie op het overmatige accent dat voorheen op de goddelijke oorsprong van de Schrift werd gelegd. De pendel slaat dan door naar de andere kant. Toch is het de vraag of men daarmee het verschijnsel verklaard heeft. Naar mijn gedachte kan men het zware accent op de menselijkheid van de Schrift niet los zien van het konkurrentieschema tussen God en mens waarin de moderne theologie is terecht gekomen. Zij doet al haar best die konkurrentie van zich te zetten. Het lukt haar alleen door de menselijkheid een plaats te geven ten koste van Gods doen en laten in deze wereld. Het merkwaardige is dan dat een tegenovergestelde opvatting door haar nu juist als konkurrentie-verhouding wordt voorgesteld. Onze konklusie is dan: het hangt er maar van af, wie welk etiket plakt. In elk geval zal men de krisis rond het Schriftgezag niet kunnen peilen, als men geen oog heeft voor het zware accent dat op de mens en zijn bijdrage aan de geschiedenis in de moderne theologie wordt gelegd. 
Men moet zelfs zeggen, dat vanuit dit gezichtspunt gezien het roomskatholieke synergisme nog een gematigde oplossing is. Vaak slaat men nog verder door en blijft er van Gods bijdrage niet veel meer over dan dat $\mathrm{Hij}$ ons de ruimte geeft om onszelf te zijn.

Het verzet tegen het oude synergisme was een typisch reformatorische aangelegenheid. Dat mag ook gezegd worden van wat ingebracht wordt tegen het moderne konkurrentieschema.

Wat is de moderne theologie? Hoe ziet ze eruit? Wie kan in enkele pennestreken haar portret tekenen? Ik zou aan vier punten het beeld van de moderne theologie willen ophangen. Natuurlijk zou men om volledig te zijn elke locus van de dogmatiek moeten beschrijven. Dat is in dit kader niet wel mogelijk. Daarom beperken we ons tot vier punten, die karakteristiek mogen heten voor de moderne theologie.

\section{Die christologie}

Daar is in de eerste plaats de christologie. Er is een geweldige drang om af te komen van de belijdenis van Chalcedon. Het werk van de Leidse dogmatikus $\mathbf{H}$. Berkhof is daarvoor karakteristiek. Hij schrijft - zij het in de kleine letter van zijn boek - dat hij van de tweeheid: vere deus, vere homo, beslist af wil. Hij kan er niet meer mee overweg. Jezus is in zijn boek wel een nieuwe schepping, maar niet de Zoon, die van hetzelfde wezen als de Vader is. Hij staat volledig aan de kant van de mensen, al is $\mathrm{Hij}$ meer dan een van ons op God gericht. In dat laatste overtreft $\mathrm{Hij}$ allen en gaat $\mathrm{Hij}$ allen voor. Resultaat van de nieuwere christologie is een beeld van Jezus als mens bij uitnemendheid, ook van het menszijn in zijn diepten en pijn, in zijn lijden en strijden, Jezus het voorbeeld, de Voorloper, de hoogste exponent van het menszijn, tegelijk op de diepste wijze solidair met allen. Hij is een van ons, en juist daarin heet Hij Gods Zoon.

Zijn werk wordt dienovereenkomstig beschreven. Het is niet gericht op God, maar naar de mensen. Dat is de kern van de wending die bijvoorbeeld Wiersinga in zake de verzoeningsleer voltrok. De spits is niet meer naar boven, op God gericht. De spits is horizontaal. Hoewel Marcuse het heel anders bedoelde, zou ik hier nu van de "one dimensional man" willen spreken. Alleen de dimensie van deze aarde.

Het is geen wonder dat het zover kwam. Wie de eerste Adam uit Genesis 1 niet kent, moet toch ergens Adam in de historie een plaats geven. Het is Jezus die de Adam van het begin is. Alleen staat $\mathrm{Hij}$ niet aan het begin. Hij komt halverwege in het midden van de geschiedenis. Hij is dé mens. Het is daarom een ééndimensionale geschiedenis, omdat $\mathrm{Hij}$ in de lijn van de ontwikkeling het hoogtepunt is. In elk geval geldt er zowel ten aanzien van de persoon als van het werk van Christus een totaal ander schema dan dat waarin tot heden de christologie gevat werd. Het is juist dit evolutionistische, ééndimensionale schema, waaruit de aanpassing bij de denk- en gevoelswereld van onze tijd duidelijk blijkt. 


\section{Het lijden van God}

Op een ander punt valt dit te verduidelijken aan de hand van de leer over God. Moltmann heeft de gedachte van de gekruisigde God naar voren gehaald. Het is een oude dwaling. Kennelijk heeft men in de eerste eeuwen van de kerkgeschiedenis die mogelijkheid ook al onder ogen gezien als een oplossing voor de problemen waaraan kerk en wereld leden. Verschil met de situatie van nu is, dat toen deze conceptie als ketterij word afgewezen. Het theopaschitisme heeft het niet gehaald in de kerkgeschiedenis. Het heeft het ook niet gedaan, tot het nu in een heel nieuwe situatie de kop weer opsteekt.

De gedachte van de lijdende God kan in onze tijd niet los gezien worden van de stelling dat God naar zijn wezen Verbondsgod is. Dat de kategorie van het verbond met God in verband wordt gebracht is een heel bijbelse zaak. Jahweh is de God van het verbond. Dat God naar zijn wezen een Verbondsgod is, is meer dan de Bijbel waar wil hebben. Hij kiest ervoor om met de mens het verbond op te richten. Zijn keus is zijn vrijheid, die niet strijdt met zijn wezen, maar ook niet met zijn wezen samenvalt. Wie Gods wil tot zijn wezen maakt, doet tekort aan de vrijheid van God, zo heb ik van Bavinck geleerd.

Welnu, wanneer het partner-zijn van God tot zijn wezen behoort, is de konklusie onvermijdelijk, dat Gods geschiedenis met die van zijn partner(s) is samengeweven. Dan kunnen we uitdrukkingen begrijpen als: God is er nog niet. Berkhof zegt het letterlijk: God is nog niet almachtig. Hij komt wel zover aan het eind. Maar nu kan dat nog niet van Hem gezegd worden. Wiersinga heeft als enige troost dat God wat langere adem heeft dan wij hebben. Daarom mogen we hoop hebben dat $\mathrm{Hij}$ er door heen komt, en wij met Hem. Meer hebben we ook niet. De gedachte van de lijdende God zie ik als de projektie van onze onmacht op God, op zijn wezen. Hoe zullen we het geloof in God aanvaardbaar kunnen maken in deze eeuw van zoveel verschrikkingen? Dat geloof is alleen te "verkopen”, als we gewagen kunnen van een God die net als wij het ook niet meer weet. Die zelf met ons, en wellicht zelfs om ons lijdt. In elk geval een God die niet vreemd is aan ons. Daarom behoeven wij ook niet vreemd te zijn aan Hem. Immers, Hij gaat ook door het lijden heen, net als wij. Hij is er ook (nog) niet, evenmin als wij er al zijn. God en mens in een partnerschap zo nauw verbonden dat beider geschiedenis aan elkaars lot onlosmakelijk verbonden is. Dat is de moderne versie van het oude theopaschitisme. Het komt echter goed met God. Daarom komt het ook goed met ons.

\section{De aard van het heil}

Een derde gezichtspunt is dat van het karakter van het heil. In Europa is het "in" om te zeggen: heil, dat door mensen niet als heil ervaren wordt, is geen echt heil. De menselijke ervaring is mede bepalend voor het wezen van het heil. Kuitert is in een recent opstel zelfs zover gegaan dat hij drie kriteria opstelde waaraan 
heil moet voldoen, om heil van God te kunnen zijn. Hij memoreerde wel dat een christen hierboven uitgaat met zijn heilsbeleving. Maar zonder deze onderbouw van aardse heilservaring kan het goddelijke heil in elk geval niet. Op welk punt christelijk heil boven dit minimum uitgaat, werd niet eens onder woorden gebracht. Dat was kennelijk voor het geheel niet meer beslissend.

Direkt hiermee verbonden is de gedachte dat men als nietchristen moet kunnen verifiëren of de bijbelse boodschap waar is. Wanneer de kerk over heil spreekt, en het blijkt een heil te zijn dat geheel buiten onze ervaringshorizon omgaat, dan kan men toch niet meer van waarachtig heil spreken. Een merkwaardige redenering. Alsof de Bijbel niet zijn eigen waarheid mocht meebrengen. Alsof de waarheid en waarachtigheid van de bijbelse boodschap zou bestaan bij de gratu ons fiat aan zulk een waarheid. Gezien de grote verscheidenheid van meningen moet men dan tegelijk wel zeggen, dat men nimmer tot een eenstemmig antwoord komt omtrent hetgeen waarheid is. Wie de bijbelse waarheid wil afmeten aan een aardse verifikatiekriterium, zal eerst intern een robbertje moeten vechten over de vraag welk kriterium daarvoor toereikend is.

Dit is al te dwaas. Een natuurlijk mens verstaat niet de dingen van God, zo schrijft Paulus in 1 Korinthe 2. Het is juist de Geest die ons de dingen van God openbaart. Het gaat niet zonder de breuk, niet zonder de overgave, de bekering, de wedergeboorte. We hebben het niet uit onszelf. Het moet ons geschonken worden. Het wordt ons toegezegd. Geloof betekent voor die toezegging ons buigen. Wie een ongelovige evenveel recht geeft om over de waarachtigheid van het heil te oordelen als aan een gelovige, miskent de hemelse oorsprong van het heil. Zulk een miskenning hangt samen met de verwaarlozing van de faktor openbaring. In de gereformeerde theologie heeft deze faktor een beslissende rol gespeeld. $\mathrm{Zij}$ betekent immers dat God aan de andere kant begint, dan waar wij ons bevinden. Van die andere kant komt $\mathrm{Hij}$ met zijn spreken op ons af. Wie zich vermeet over dat spreken te kunnen oordelen zonder geloof en buiten de bekering om, werpt zich op als rechter over Gods zaken. Ook het omgekeerde moet gesteld worden: God is rechter over ons. Hij oordeelt ons. Wij hebben ons aan Hem te onderwerpen.

Geloof is geen menselijke potentie. Het is gave van de Geest van Christus. Het gaat om het recht van Gods spreken in de diskussie over de aardsheid van het heil. Het gaat niet om de rechtvaardiging van onze theologie. Merkwaardig in het verleden is tegen de theodicee sterk geopponeerd, en terecht. Wij behoeven God niet te rechtvaardigen. Wij kunnen het ook niet. Het is de hybris die tot zulk een poging verleidt. Evenmin behoeven wij een rechtvaardiging van de bijbelse heilsboodschap te geven. Wij behoeven die niet aanvaardbaar te maken. We kunnen die ook niet verklaarbaar maken. Zij heeft haar goed recht in zichzelf. $\mathrm{Zij}$ spreekt voor zichzelf. Het heil is Gods genadegeschenk aan een schuldig mens. De schuldige heeft niet aan de rechter voor te schrijven hoe de vrijspraak eruit moet zien. Daarover zal de rechter wel oordelen. 
In dit alles treffen we dan ook de sfeer van moralisme en empirisme aan, waardoor de moderne theologie uit de vorige eeuw werd gekenmerkt. De heiliging verwisselt van plaats met de rechtvaardiging. Zij gaat voorop. Het heil wordt door ons aan anderen bereid. Daarop heeft God dan nog alleen maar zijn goedkeuring te geven, bij de gratie die wij hem daartoe verlenen; in plaats daarvan dat wij van Gods gratie leven.

\section{Christelijk geloof, een vorm van geloof in het algemeen?}

Een laatste punt dat ik ter typering van het modern theologische denken wil aanraken is dat van de exclusiviteit van het christelijk geloof. Berkhof zegt het dialektisch: wel uniek, maar niet exclusief. Daarin ontmoet men een van de trefwoorden van zijn dogmatiek: bij de diskontinuïteit overheerst de kontinuiteit. Er is een diepe en direkte verbondenheid van het christelijk geloof met ander vormen van geloof. Het christelijk geloof is volgens Berkhof een sprongvariatie.

Dit is een geliefkoosd beeld in Berkhofs dogmatiek die gezet is in het kader van de evolutie. Zelfs de beeldspraak is daarmee in overeenstemming. Men kan dezelfde gedachten, zonder de beeldspraak van sprongvariatie, ook bij Kuitert aantreffen. $\mathrm{Hij}$ is zelfs nog minder zorgzaam dan bijvoorbeeld de Amerikaanse godsdienstsociologie. Daar wil men een ongelovige nog in zijn ongeloof serieus nemen. Kuitert dicht ieder mens krachtens zijn mens-zijn geloof toe. De soort van geloof doet er dan minder toe. $\mathrm{Zij}$ wordt beoordeeld naar haar effektiviteit. Wat werkt is waar; wat niet werkt, heeft geen overlevingskans. Maar er komt wel wat anders voor in de plaats. Ieder mens heeft zoiets als geloof. Daarom zal het christelijk geloof ook wel overleven; doch alleen inzoverre het blijkt te werken. De waarheid hangt af van de werking. Daarmee is het verifikatiebeginsel weer van beslissende betekenis. Hier staat de moderne theologie haaks op het gereformeerde denken. Dat heeft immers het christelijk geloof van elke andere vorm van godsdienst onderscheiden gezien doordat christelijk geloof vrucht is van de openbaring van God in Jezus Christus, zoals we die ontvangen hebben in de Heilige Schrift. We buigen hier terug naar het begin. In de leer omtrent de openbaring, beter nog bij het geloof in God die zich openbaart, valt een beslissing die heel de opbouw van de geloofsleer, en heel de visie op het heil bepaalt.

\section{Secularisatie als achtergrond}

Wanneer men nu vraagt wat de achtergrond is van deze nieuwe theologie dan moet gewezen worden op de secularisatie. De secularisatie wordt gekenmerkt door een manier van denken en handelen waarin God afwezig is. De mens staat er voor in eigen kracht en is aangewezen op zijn eigen mogelijkheden. Hij kan geen beroep doen op een instantie buiten deze wereld. Zo God al bestaat, $\mathrm{Hij}$ kan niet gekend worden. We zijn op onszelf, onze inzichten aangewezen. We moeten het zelf voor elkaar brengen. Geen kontrole 
van buiten af noch van boven; niet van enige metafysica noch van enige godsdienst, zeker niet van een buitenwereldse openbaring.

Het is duidelijk dat een poging van hieruit de theologie op te bouwen, leidt tot een resultaat als hetwelk hierboven werd beschreven. Dan krijgen we precies het „one dimensional" beeld, dat we hierboven tekenden. Men vertaalt alle onderdelen van de theologie in de taal van de secularisatie. De Reformatie heeft precies het omgekeerde gedaan. De herontdekking van het Woord was tegelijk de herontdekking van de handelende God; van zijn spreken over oordeel en vergeving, van zijn doen in gericht en genade.

Om het tot stand komen van de geseculariseerde theologie te begrijpen zal men moeten teruggrijpen op de korrelatietheologie van Paul Tillich. Zijn uitgangspunt is dat de mens die vragen stelt. Daarop moet de theologie, de Bijbel, in laatste instantie God Zelf het antwoord geven. Het lijkt een heel billijke redenering. Wie zou niet bereid zijn te erkennen, dat de theologie, vooral als ze theologie wil zijn die zich op de openbaring beroept, op de vragen van de mens moet ingaan. Toch is er een geweldige menselijke inbreng in zulk een theologie ingebouwd.

Die inbreng komt binnen via de vraagstelling. De vraag struktureert immers het antwoord. Het overkomt ieder wel eens, dat hij op een vraag geen antwoord kan geven, omdat de vraag verkeerd gesteld is; omdat de vraag zoals deze geformuleerd werd, illegitiem is. Wie nu elke mogelijke vraagstelling als recht hebbend op een bijbels antwoord beziet, miskent dat ook onze vragen en onze vraagstelling onder de kritiek van Gods openbaring moet komen. Wie weigert zijn vraagstelling onder die kritiek te laten komen, struktureert met zijn vraagstelling het antwoord. We krijgen hier de hele kwestie van de verifikatie in een andere vorm terug.

Naar onze gedachte heeft Tillich in niet onbelangrijke mate bijgedragen aan de wending die de nieuwe theologie te zien geeft. Tot heden heeft men zijn invloed onderschat. Die invloed is vooral methodisch van aard. Zijn methode brengt een bepaalde inhoud mee.

\section{Neomarxistische invloed}

Het is juist deze hele opzet van theologiseren, die de weg opent voor neomarxistische invloed. Binnen het neomarxisme zoekt men als reaktie op het koele, koude marxisme weer een stuk religieuze bezieling. Men grijpt daarvoor terug op Jezus. Niet op de Jezus, zoals Hij door de kerk der eeuwen is beleden. Er zijn tal van neomarxistische publikaties waarin duidelijk gezegd wordt dat men met die Jezus niets kan beginnen. Men grijpt terug op de „one-dimensional Jesus". De Jezus, die exempel en exponent is, die hoogtepunt en dieptepunt van het menszijn heeft voorgeleefd. Namen als die van Ernst Bloch en Gardavsky zijn in dit opzicht veelzeggend. Het neomarxisme kan een godsdienst gebruiken, waar de pit van het belijden der eeuwen uit is verdwenen, en waarin slechts de woorden herinneren aan de boodschap van de kerk. Het is met name het historisch-kritisch bijbelonderzoek dat aan een man als Bloch het materiaal heeft geleverd voor zijn vertekend beeld van de bijbelse 
boodschap. Het is voor ons beschamend dat toen hij zich met theologie ging bezig houden, hij stuitte op een theologie die hem een vertekend, erger nog, verminkt beeld van Jezus in handen gaf. De kerk heeft grote schuld in Europa doordat van binnenuit de belijdenis van Jezus ondermijnd is. Het historisch-kritisch onderzoek heeft voor de kerk zelf, maar ook voor hen die van buiten naar binnen keken, wrange vruchten afgeworpen.

\section{De Wereldraad van Kerken}

Dit alles vindt nu, zoals A. G. Honig het onlangs uitdrukte, zijn kristallisatiepunt in de theologie van de Wereldraad van Kerken. Daar treft men als in een sluis het samenkomen van deze ver. schillende stromingen van de nieuwe theologie aan. Daar worden ze tot een praxis omgesmeed, die men als (neo-)marxistisch mag kenschetsen. Het is met name de Wereldraad van Kerken die deze nieuwe, geseculariseerde theologie in praktijk weet te brengen. Haar programma tot bestrijding van het racisme, maar evenzeer haar dialoog met andere godsdiensten en ideologieën, zijn de praktische verwerking van deze „one dimensional theologie”, naar het model van het moderne Jezusbeeld. Men kan de invloed van deze praktijken, die naar een bepaald theologiemodel gestruktureerd zijn, niet licht overschatten.

Aansluiting bij de Wereldraad van Kerken betekent dan ook dat men eigen kerkelijk leven voor deze invloeden openstelt. Er wordt nogal eens hoog opgegeven van wat kerken aan inbreng kunnen hebben binnen het geheel van de Wereldraad van Kerken. Tot heden is niet gebleken dat enige kerk van gereformeerde huize kans gezien heeft het beleid om te buigen en in Genève een andere koers tot stand te brengen. Het geschiedt helaas veeleer in omgekeerde lijn. De daar uitgestippelde koers wordt binnen de verschillende lidkerken wettig ingebracht. Wie kan zich daartegen verzetten, wanneer hij het lidmaatschap van de Wereldraad van Kerken met overtuiging bepleit tegen alle mogelijke gerechtvaardigde kritiek?

De Wereldraad van Kerken heeft naar buiten en naar binnen grote betekenis door het praktiseren van deze nieuwe theologie. Het betekent niet minder dan een aanslag op het gereformeerde leven en denken van kerken die zich in haar invloedsfeer bevinden.

\section{Positieve opstelling vereist}

Wat zullen we hier tegenover stellen? Laat ons beginnen met de belijdenis van het Koningschap van God over deze wereld. We zitten wel in chaotische toestanden. We weten er soms geen weg in te vinden en we weten er soms niet meer wijs uit te worden. Niettemin belijden we dat God Koning is. Het Koninkrijk van Jezus Christus is werkelijkheid, ook al wordt dat Koningschap nog weerstaan. We zullen uit reaktie tegen de verminking van Jezus' boodschap ons niet mogen terugtrekken op het innerlijk. Nog minder zullen we de strijd mogen staken, alsof ze toch verloren was. Ze is juist gewonnen. De opstanding van Christus is daarvan bewijs en bezegeling. 
Hij verbrak de macht van de dood, en van alles wat daarachter lag: de zonde en de schuld tegenover God.

Christus is Koning. Zijn Rijk komt, Dat is het beslissende in de wereldgeschiedenis. We moeten niet moedeloos worden. We zullen ons positief moeten opstellen.

Dat Koninkrijk kunnen we alleen belijden, als we vasthouden aan de openbaring die van buiten onze wereld komt. God is niet maar objekt van openbaring, zodat wij over Hem als objekt kunnen beschikken. Hij is Subjekt die Zichzelf door mensen in deze wereld openbaart. Daar ligt aan het begin reeds het punt van scheiding. Wie over openbaring enkel binnenwereldlijk wil spreken, spreekt over God in kategorieën van menselijke zelfopenbaring. Hij zal zich niet kunnen verzetten tegen de gedachte dat geloof projektie is van het eigen innerlijk.

Alleen waar God beleden wordt als Soeverein Subjekt die in deze wereld spreekt en handelt, kan men het verwijt van projektie pareren. Anders niet. Daarom is met de leer over de Schrift het fundament van heel de theologie in het geding.

Daarbij voegt zich als tweede punt de belijdenis dat het heil van hemelse oorsprong is. Het komt niet op uit de mens. Het wordt ons ook niet door mensen bereid. God is de oorsprong ervan. Ook hier blijkt de geweldige tegenstelling met een geseculariseerde theologie. Wie van niets anders dan ondermaans weet te spreken, zal het heil „one dimensional" maken. Laat ons bedenken dat zulks komt te staan op het verlies van het hemels karakter van het heil. Zelfs al komt dat heil weer uit de hemel naar de (nieuwe) aarde, dan blijft het karakter ervan hemels. Dat is toch eigenlijk wat Openbaring bedoelt, als we lezen dat het Nieuwe Jeruzalem uit de hemel neerdaalt.

Daarnaast zullen we aandacht hebben te geven aan de heiliging. We mogen uit reaktie haar niet voorbijzien en waardeloos achten. Juist als dat geschiedt, ontstaat een voedingsbodem voor ideologieën die begrepen hebben hoezeer het heil de samenleving van mensen wil veranderen. De uitdaging van moderne ideologieën zullen we niet kunnen beantwoorden zonder op de heiliging, persoonlijk en in samenlevingsverbanden, nadruk te leggen. Het moet dan echter wel geschieden in de bijbelse, onomkeerbare volgorde van rechtvaardiging en heiliging. De vrijspraak van God is het die tot het leven in de liefde in staat stelt. Het is niet het nieuwe leven waaruit blijkt dat we rechtvaardig zijn. Dan zal men elke vorm van nieuw leven moeten aanzien voor een vrucht van het geloof. Het is alleen het geloof in Jezus Christus dat de rechte vruchten der dankbaarheid voortbrengt. Wil men van verifikaties spreken, dan zal het altijd moeten geschieden binnen de bekende figuur van de syllogsimus practicus. Het is de sluitrede van het geloof. Niet de sluitrede van de rede, die verifikatie mogelijk maakt.

Een laatste punt is de belijdenis van de wederkomst van Christus. Die belijdenis wordt in de moderne theologie omgebogen naar de gedachte dat ons doen Christus laat wederkomen. Zijn komst valt dan samen met onze arbeid tot voltooiing van de aardse 
geschiedenis. Niet aldus het bijbelse kerygma. Daarin is de wederkomst van Jezus Christus tegelijk het gericht. Dat gaat zelfs over de werken der gelovigen. Paulus schrijft daarover heel duidelijk in 1 Korinthe 3 .

Dan ben ik tegelijk aan het einde. Gereformeerde theologie wil eschatologische theologie zijn, wijl ze weet dat haar bestaan niet verder reikt dan tot de dag van de wederkomst. Ze wil bewust op die wederkomst betrokken zijn, tot in de opbouw van de theologie toe. Het is een voorrecht om temidden van deze verwarde theologieën koers te houden op het kompas van de gereformeerde theologie. $\mathrm{Er}$ is maar éen theologie die de stormen overleeft en het houdt tot de jongste dag: dat is de gereformeerde theologie.

Op verzoek van de redaktie heb ik de hoofdlijnen neergeschreven van een voordracht die ik op 30 augustus 1976 hield voor de vergadering van gereformeerde predikanten in Pretoria. Op 31 augustus en 1 september werd deze zelfde voordracht gehouden voor studenten aan de theologische faculteit van Pretoria en Potchefstroom. Omdat ik van enkele aantekeningen sprak, was het niet mogelijk de tekst van mijn voordracht letterlijk te reproduceren.

Bij deze voordracht heb ik gebruik gemaakt van een deel van de lezing welke ik voor de theologische konferentie van de Reformed Ecumenical Synode in Kaapstad heb gehouden, op 7 augustus 1976. De tekst van die lezing als ook de vermelding van literatuur zal eerlang verschijnen in het International Reformed Bulletin. Voor nadere verantwoording van mijn standpunt zij daarheen verwezen.

(Voordrag gelewer deur prof. W. H. Velema van Apeldoorn voor die GTV Pretoria, Augustus 1976) 